\title{
A qualitative study of patients' goals and expectations for self-management of COPD
}

\author{
*Kathryn Wortz', Angela Cade', James Ryan Menard', Sue Lurie ${ }^{2}$, Kristine Lykens ${ }^{3}$, \\ Sejong Bae ${ }^{4}$, Bradford Jackson ${ }^{4}$, Fenghsiu Su${ }^{5}$, Karan Singh ${ }^{4}$, David Coultas ${ }^{6}$
}

${ }^{1}$ The University of Texas Health Science Center at Tyler, Department of Family Medicine, Tyler, Texas, USA

2 The University of North Texas Health Science Center, School of Public Health, Department of Behavioral and Community Health,

Fort Worth, Texas, USA

${ }^{3}$ The University of Texas Health Science Center, Health Management and Policy Department, Fort Worth, Texas, USA

${ }^{4}$ The University of Alabama at Birmingham, Department of Medicine, Division of Preventive Medicine, Birmingham, Alabama, USA

${ }^{5}$ The University of North Texas, School of Public Health, Department of Biostatistics, Fort Worth, Texas, USA

${ }^{6}$ The University of Texas Health Science Center at Tyler, Department of Medicine, Tyler, Texas, USA

Received 5th March 2012; revised 18th May 2012; accepted 27th June 2012; online 8th November 2012

\begin{abstract}
Background: Chronic obstructive pulmonary disease (COPD) is an illness that affects patients on multiple levels, both physically and psychologically. While there is a growing body of evidence for the efficacy of self-management among patients with COPD, little evidence is available on the optimal content and methods for delivering self-management support.

Aims: The purpose of this study was to address gaps in the literature on self-management support by examining patients' responses to questions about goals, needs, and expectations regarding self-management using qualitative methods in a broadly representative sample of patients with moderate to severe COPD. By focusing on patients' perceptions of their needs, we hoped to guide development of cognitive-behavioural interventions for self-management support.

Methods: Patients $\geq 45$ years of age with a physician diagnosis of COPD were recruited as part of a larger randomised controlled trial designed to determine the effectiveness of a lifestyle behavioural intervention to increase physical activity. In-depth interviews were conducted at baseline data collection using 10 standardised open-ended questions tailored to examine factors relevant to selfmanagement support including concerns, fears, learning needs, barriers, facilitators, and goals. All interviews were audio recorded and analysed using qualitative methods. Responses were coded by three raters into thematic categories.

Results: A sample of 47 interviews with patients of mean age 68.4 years, $53 \%$ male, $87 \%$ white were used in the analysis. The distribution of spirometric impairment based on percent predicted forced expiratory volume in 1 second (FEV 1 ) was moderate (57.5\%), severe (31.9\%), and very severe (10.6\%). In response to questions targeting needs and goals for care, three main themes (loss, fear, and desire for improved care) and seven associated sub-themes were identified. Because of breathlessness and fatigue as well as symptoms from conditions other than COPD, patients reported the loss of ability to participate in pleasurable and necessary activities of daily living and the desire to recover at least some of their functioning. They expressed problems with social isolation and uncertainty about their prognosis, as well as the hope to improve. In addition, fearful experiences associated with uncontrolled breathlessness and a wish for greater understanding and knowledge about treatment were major concerns.
\end{abstract}

Conclusions: These qualitative results suggest that the content of self-management support for patients with COPD should focus on addressing patients' fears associated with the uncertainty, progression, and suffering of their disease, their expectations about overcoming or replacing losses, their needs for improved health literacy and their desire for improved care. These responses indicate areas where cognitivebehavioural intervention should focus in order to enhance patient self-efficacy, motivation, and behavioural change for improved selfmanagement.

(C) 2012 Primary Care Respiratory Society UK. All rights reserved.

K Wortz et al. Prim Care Respir J 2012; 21(4): 384-391

http://dx.doi.org/10.4104/pcrj.2012.00070

Keywords chronic disease, cognitive-behaviour, COPD, qualitative research, self-management

\footnotetext{
* Corresponding author: Dr Kathryn Wortz, The University of Texas Health Science Center at Tyler, Department of Family Medicine, 11937 U.S. Hwy 271, Tyler, TX 75708, USA. Tel: 9038777248 Fax: 9038777778 E-mail: kathryn.wortz@uthct.edu
} 


\section{Introduction}

Chronic obstructive pulmonary disease (COPD) is a major cause of morbidity and mortality, and a source of substantial personal suffering worldwide. ${ }^{1}$ In the past decade, a growing number of efficacious pharmacological and non-pharmacological interventions have become available.' Despite these medical innovations, the management of COPD is often suboptimal ${ }^{2}$ and may be explained by a number of determinants at the level of the patient, physician, healthcare system, and community. ${ }^{3}$

The chronic care model provides a framework for understanding and addressing gaps in chronic illness care, and there is a growing body of evidence that supports the effectiveness of this model. ${ }^{4}$ The chronic care model defines the multipronged approach required to optimise outcomes and recognises that the majority of effort for management of chronic conditions falls to the patient, termed 'selfmanagement'.

Self-management support has been defined as 'the systematic provision of education and supportive interventions by healthcare staff to increase patients' skills and confidence in managing their health problems, including regular assessment of progress and problems, goal setting, and problem-solving support'. ${ }^{5}$ The goals of self-management are behaviour changes to promote improved functioning and quality of life. However, while there is a growing body of evidence for the efficacy of self-management strategies (e.g. patient education, coping skills, action plans for exacerbations, exercise programmes) among patients with $\mathrm{COPD}^{6}$ few interventions have been specifically designed to promote and sustain behaviour change. ${ }^{?}$

The determinants and processes associated with selfmanagement behaviours are complex, comprising a number of factors such as health beliefs, self-efficacy, and motivation. These factors have been examined in a number of studies of patients with COPD using qualitative and quantitative methods, but these studies have not been designed nor the results used for development of cognitive-behavioural interventions. Such studies are lacking in the literature on self-management support of COPD. ${ }^{7}$ To address this gap, we conducted a self-management needs assessment of patients with COPD eligible for pulmonary rehabilitation and are using this information in a randomised trial of a self-management behavioural intervention to promote physical activity. The purpose of the analysis in this paper is to describe the results of this qualitative needs assessment to guide development of cognitive-behavioural interventions for self-management support of patients with COPD.

\section{Methods}

This qualitative study was conducted at the University of Texas Health Science Center at Tyler (UTHSCT) as part of a larger randomised controlled trial to determine the effectiveness of a lifestyle behavioural intervention to increase physical activity among patients with COPD. ${ }^{8}$ UTHSCT is one of five health systems in an eight county region in east Texas and had over 100,000 outpatient physician visits in 2010.

\section{Participant selection and setting}

Patients aged $\geq 45$ years with a physician diagnosis of COPD were recruited for the trial using two methods: a patient registry and physician referrals. These patients were cared for by 14 primary care physicians, two physician assistants, and seven pulmonary physicians. The registry was created from an administrative database comprised of all patients seen at the clinics of UTHSCT with a coded COPD diagnosis (ICD-9 491, 492, 496) prior to August 2009. The study was approved by the UTHSCT Institutional Review Board.

The goal was to recruit a sample of patients broadly representative of COPD patients eligible for pulmonary rehabilitation. Eligibility was initially determined from review of medical records including spirometry results and for other clinical characteristics that may prevent participation (Table 1). Potentially eligible subjects were sent an introductory letter of invitation to participate and subsequently contacted by telephone to schedule an enrolment visit. After obtaining written informed consent, final determination of eligibility was made using the inclusion and exclusion criteria described in Table 1.

\section{Data collection and analysis}

At the enrolment visit, baseline demographic, clinical and selfmanagement needs assessment data were collected for the randomised trial. Clinical data used to characterise the patients included smoking status, spirometry, 6-min walk distance, Body Mass Index, Obstruction, Dyspnea, Exercise Capacity (BODE) ${ }^{9}$ index, Chronic Respiratory Questionnaire (CRQ) ${ }^{10}$ and Geriatric Depression

Table 1. Inclusion and exclusion criteria for patients interviewed with COPD

Inclusion

\begin{tabular}{l} 
Age $\geq 45$ years \\
\hline Physician diagnosis of COPD \\
\hline $\mathrm{FEV}_{1} / \mathrm{FVC}<0.70$ and $\mathrm{FEV}_{1}<70 \%$ \\
$\mathrm{MMRC}_{\text {dyspnoea score }} \geq 2$
\end{tabular}

Exclusion

Participation in pulmonary rehabilitation program within 12 months

Nursing home resident

Uncontrolled hypertension, angina, heart failure

Unstable ECG findings (e.g. uncontrolled dysrhythmia, active ischaemia)

Dementia, uncontrolled psychiatric illness

Life expectancy $<12$ months

Resting oxygen saturation $<90 \%$ and inability to obtain supplemental oxygen

6-min walk $<110$ metres

Other safety concerns with participating in physical activity 


\section{Box 1. COPD self-management needs assessment}

The goals of this self-management programme are to provide you with information that will help you gain confidence to live better with your COPD. The first step is to find out what you want to know and also determine what you need to know to manage your illness. Answering these questions will help us develop a plan together.

1. What is your greatest concern or fear about your COPD?

2. From your past experience with COPD, what things have helped you most to control/manage your illness?

3. What other things do you think you need to learn to help you live with COPD?

4. What may get in the way of controlling your illness?

5. Describe who currently helps you manage your COPD and how they help.

6. What is your most important goal for helping you live better with your COPD?

To better assist you, I am going to ask questions with regard to physical activity and exercise.

1. Since being diagnosed, what have you done to help manage your COPD?

2. From your past experiences, what are some things that may prevent you from being physically active?

3. What groups or people do you have in place to help increase your physical activity?

4. What types of physical activity do you enjoy?

Scale. ${ }^{11}$ For the self-management needs assessment, one trained interviewer (JP) conducted and audio-taped patient interviews in the outpatient area of UTHSCT using 10 standardised open-ended questions (Box 1). The focus of the questions was on goal setting, expectations, social support, and individual needs with the aim of learning about individual goals for the future (e.g. overcoming losses and fears) that were used to tailor subsequent counselling using cognitive-behavioural techniques to enhance COPD selfmanagement and physical activity. The audio recordings provided the raw data for this analysis. On average, the interviews lasted 27 mins (range 15-42).

The interviews of 54 patients from April 2010 through January 2011 were randomly selected for inclusion in this qualitative analysis. The characteristics of these patients are described in Table 2. All

Table 2. Characteristics of patients with COPD interviewed $(n=54)$

\begin{tabular}{|c|c|c|c|c|}
\hline Characteristic & & Included $(n=47)$ & Excluded $(n=7)$ & $\mathrm{p}$ value \\
\hline Mean (SD) age, years & & $68.4(9.3)$ & $70.3(9.0)$ & 0.83 \\
\hline Female $(\%)$ & & 46.8 & 42.9 & 1.00 \\
\hline Race $(\%)$ & $\begin{array}{l}\text { White } \\
\text { Black } \\
\text { Other }\end{array}$ & $\begin{array}{l}87.2 \\
10.6 \\
2.1 \\
\end{array}$ & $\begin{array}{l}85.7 \\
14.4 \\
0 \\
\end{array}$ & 1.00 \\
\hline Education (\%) & $\begin{array}{l}<\text { High school } \\
\text { High school } \\
>\text { High school }\end{array}$ & $\begin{array}{l}21.3 \\
29.8 \\
48.9 \\
\end{array}$ & $\begin{array}{l}0 \\
43.9 \\
57.1 \\
\end{array}$ & 0.50 \\
\hline Residence (\%) & $\begin{array}{l}\text { Urban } \\
\text { Rural } \\
\text { Unknown }\end{array}$ & $\begin{array}{l}49.0 \\
40.4 \\
10.6 \\
\end{array}$ & $\begin{array}{l}57.1 \\
42.9 \\
0 \\
\end{array}$ & 1.00 \\
\hline $\mathrm{FEV}_{1} \%$ predicted (\%) & $\begin{array}{l}<70-\geq 50 \% \\
<50-\geq 30 \% \\
<30 \%\end{array}$ & $\begin{array}{l}57.5 \\
31.9 \\
10.6 \\
\end{array}$ & $\begin{array}{l}71.4 \\
28.6 \\
0 \\
\end{array}$ & 1.00 \\
\hline Smoking status (\%) & $\begin{array}{l}\text { Current } \\
\text { Former } \\
\text { Never }\end{array}$ & $\begin{array}{l}25.5 \\
63.8 \\
10.6 \\
\end{array}$ & $\begin{array}{l}14.3 \\
85.7 \\
0 \\
\end{array}$ & 0.83 \\
\hline Mean (SD) co-morbidities & & $3.0(2.0)$ & $3.0(1.3)$ & 0.98 \\
\hline Mean (SD) BODE index & & $4.3(2.0)$ & $3.14(1.8)$ & 0.16 \\
\hline Mean (SD) CRQ & $\begin{array}{l}\text { Dyspnoea } \\
\text { Fatigue } \\
\text { Emotion } \\
\text { Mastery } \\
\text { Total }\end{array}$ & $\begin{array}{l}4.5(1.2) \\
3.7(1.1) \\
4.5(0.8) \\
4.3(0.8) \\
4.3(0.7)\end{array}$ & $\begin{array}{l}4.6(0.9) \\
3.9(1.5) \\
4.8(0.8) \\
4.5(0.7) \\
4.5(0.7) \\
\end{array}$ & $\begin{array}{l}0.74 \\
0.59 \\
0.27 \\
0.55 \\
0.38 \\
\end{array}$ \\
\hline Mean (SD) 6-min walk (metres) & & $337.7(94.2)$ & $356.8(79.2)$ & 0.61 \\
\hline Geriatric Depression Scale (\%) & $\begin{array}{l}\text { None }(0-5) \\
\text { Moderate }(6-10) \\
\text { Severe }(>10)\end{array}$ & $\begin{array}{l}74.5 \\
23.4 \\
2.1 \\
\end{array}$ & $\begin{array}{l}71.4 \\
28.6 \\
0\end{array}$ & 1.00 \\
\hline
\end{tabular}

BODE=body mass index (weight $(\mathrm{kg}) /$ height $\left(\mathrm{m}^{2}\right)$, obstructive airway impairment, dyspnoea level, exercise capacity, ${ }^{11} \mathrm{CRQ}=\mathrm{Chronic}$ Respiratory Questionnaire, ${ }^{12}$ $\mathrm{FEV}_{1}=$ forced expiratory volume in 1 second, $\mathrm{SD}=$ standard deviation. 
Figure 1. Process for coding of patient interviews

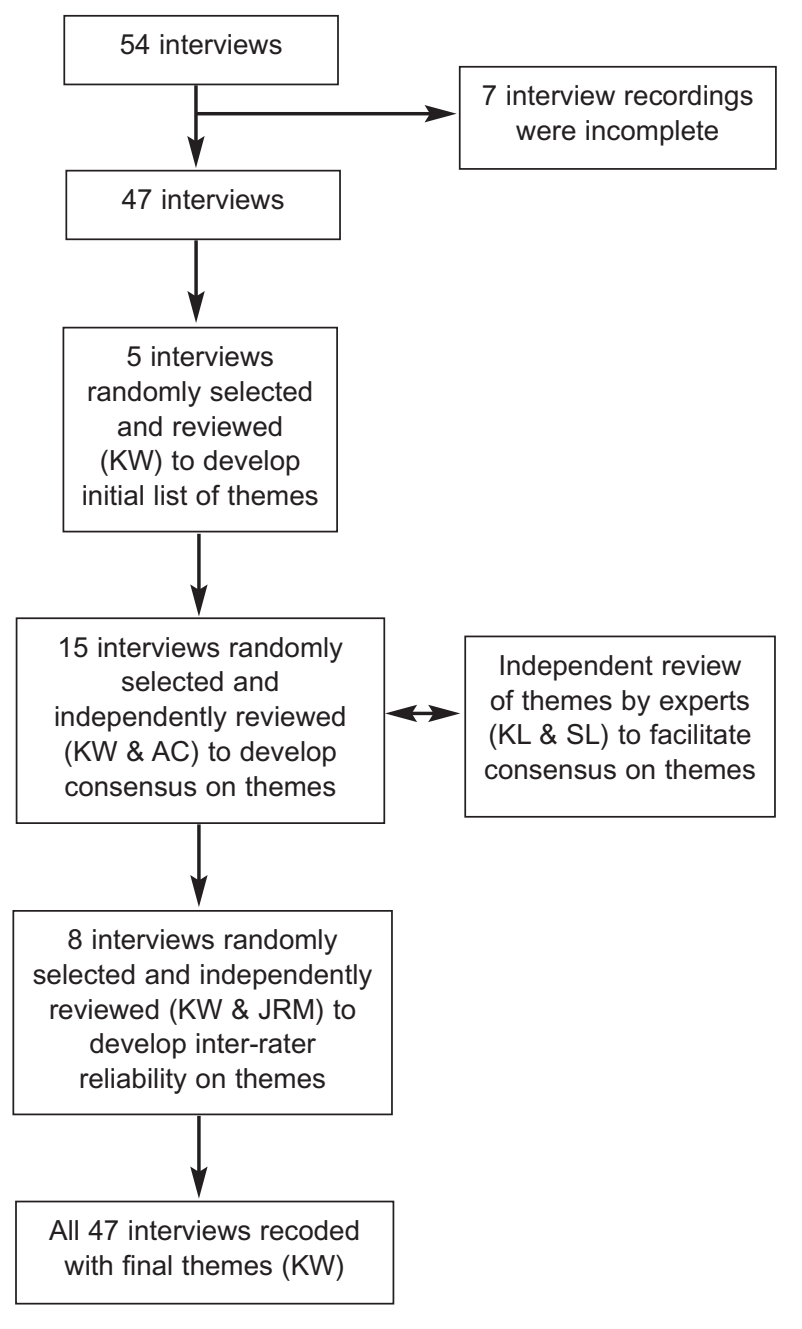

interviews were initially reviewed by one coder (KW) for quality and, of the 54 recorded interviews, seven were eliminated because they were incomplete due to interruptions or technical problems. Initially the audio recordings were transcribed; however, because the written transcripts were determined to be insufficient to understand and capture the speaker's meaning fully (i.e. intonation and flow [prosody]), analysis of the interviews was conducted directly from the audio recordings by all coders.

The process for analysing the interviews and theme development involved three coders ( $\mathrm{KW}, \mathrm{AC}, \mathrm{JRM}$ ) and two experts $(\mathrm{SL}, \mathrm{KL})$ in qualitative analysis (Figure 1). Each rater reviewed the recorded interviews, noted responses, and coded themes independently. All quotations for this report were transcribed word for word.

Responses were initially coded into non-hierarchical thematic categories in an inductive approach using grounded theory methods. ${ }^{12,13}$ The initial non-hierarchical categories were derived by one coder (KW) from five interviews. These five interviews were selected at random from the group and served to form a 'first impression' of recurring themes. These categories or themes were then applied to 15 additional interviews; new categories were added and former categories were renamed as necessary to fit the additional data. A second rater $(\mathrm{AC})$ was then introduced into the process. Nine non-hierarchical categories were developed by consensus of the two raters. These were then independently reapplied in a blind fashion by both raters to the 15 audio files. However, concordance of selected themes was unsatisfactory, ranging from $25 \%$ to $100 \%$.

To address the variation in coding of themes by the two coders $(\mathrm{KW}, \mathrm{AC})$, two experts in qualitative data analysis $(\mathrm{KL}, \mathrm{SL})$ were engaged and met with the coders to review the codes. As a result, the themes were collapsed and consolidated into a hierarchical coding tree with major and minor sub-themes (Table 3). Using this revised coding framework, a new sample of interviews $(n=8)$ was independently coded by KW and a third coder (JRM). Since the interrater reliability was high, these final themes were used by KW to recode all interviews and further validation of themes was provided from review by the interviewer (JP).

\section{Results}

The sample of 47 patients used in this analysis represented a range of characteristics including age, gender, social factors, severity of impairment, and co-morbidities (Table 2). Overall, the patients were older (mean age 68.4 years) and white (87\%), with a slightly higher proportion of males than females ( $53 \%$ vs. $47 \%$, respectively). Approximately half (51\%) had a high school education or less, and about $40 \%$ resided in rural areas. The distribution of impairment of percent predicted forced expiratory volume in 1 second $\left(\mathrm{FEV}_{1}\right)$ was moderate $(57.5 \%)$, severe $(31.9 \%)$, and very severe $(10.6 \%)$. Moreover, on average the BODE index was mid-range (4.3 on a 10point scale $)^{9}$ and patients reported moderate-to-severe functional impairment from dyspnoea (mean CRQ-dyspnoea score 4.5$)^{10}$ and three co-morbid conditions.

The coding of the interviews yielded three major themes including loss, fear, and desire for improved care (Table 3). These major themes were composed of seven sub-themes including four associated with loss, two with fear, and one with desire for improved care. The concordance of sub-themes suggested that these hierarchical categories provided comprehensive, distinct, and clear categories with good inter-rater reliability $(r=0.837, p<0.01$; Table 3$)$. These three themes and associated seven sub-themes are described in greater detail below.

Loss

The loss theme comprised four sub-themes including loss of normal functioning, loss of independence, loss associated with other medical conditions, and loss of social contacts (social isolation). Among the 47 patients, the frequency with which the various loss sub-themes was expressed ranged from $40 \%$ to $96 \%$ (Table 3). The two most frequently voiced concerns were about loss of normal functioning (96\%) and loss associated with other medical impairments (79\%).

Concern about loss of normal functioning was characterised by the loss of normal activities not necessarily essential to survival, such as performing recreational activities and hobbies or the inability to complete tasks in a normal fashion or at a normal pace. This loss was 
Table 3. Thematic categories of interviews from patients with COPD



often attributed to breathlessness and fatigue.

1. "I used to enjoy dancing ... can't do that anymore ... can't make it through a song." (BL7976R)

2. "Lots of thing I like to do, but I can't. We used to dance a lot. Our main activity now is going to the grocery store and the hospital." (EL6831W)

3. "I would like to play golf, things like that, but I'm just not able to do it." (MH9174T)

4. "I want to basically get back to the level ... [where I was before] ... get as healthy as I can." (HWTM\#4697)

5. "I have very young grandchildren and I'd like to be able to keep up with them." (KM9108W)

The loss of normal functioning associated with symptoms from COPD also contributed to concerns about loss of independence characterised by the inability to perform tasks necessary for daily living such as shopping, bathing, and keeping house.

1. "Sometimes my house is a disaster I think because I'm not able to mop." (SW9911L)

2. "[I fear] getting down where I can't live by myself." (DD6850S)

3. "The vacuum cleaner de-winded me; sweeping is just as bad. I can't bend over ... I can't raise my arms up or I lose my air, so I'm just really a helpless person." (EL6831W)

4. "They told me they couldn't let me go home without oxygen and that kind of made you ... I felt like I was trapped - that you were gonna have to have oxygen, you know." (JT8499)

In addition to the loss of functioning associated with their COPD, patients frequently reported other medical conditions that interfered with their ability to be active.

1. "I know I need to exercise more, but that's kind of hard to do when your foot hurts and your back hurts and your breathing hurts." (HM8510X)

2. "My legs bothers [sic] me when I walk, and my hips. That's the reason I have to hold on to something if I walk very far." (NG5273F)

3. "I know I could exercise and that would make it better, but I'm not doing that now. I don't know, the depression it kindly like puts you in handcuffs or something." (PJ7261P)

The symptoms associated with COPD and other chronic conditions contributed to reduction in social activities and feelings of social isolation. Moreover, they expressed concern about a lack of, or inadequate, social support.

1. "One thing that really sets my stuff off is like when I go to church and people have on perfume... you can't get along with that." (CN5291A)

2. "No one's even aware I have COPD." (RA7413G)

3. "I got a son here, but ... I don't have many [people]. You know, they work and everything ... but I got to where I read a lot." (JM8520H)

\section{Fear}

The theme of fear was frequently expressed and comprised fear about disease progression (70\%) and suffocation (51\%). Fear of disease progression was characterised by concerns about the future of one's illness and uncertainty as to how to prevent progression of the disease.

1. "I'm never gonna get better, I know that. Sometimes I think I'm getting worse." (HM8510X)

2. "I don't want to be an invalid on oxygen all the time. I just don't want that to happen." (MM5352P) 
3. "[I'm afraid] that it'll get worse. [I want to learn] more things to keep me from getting worse and to help me control it better." (NL8925A)

Patients frequently reported experiences of severe breathlessness associated with intense panic and fear. Moreover, these episodes contributed to fear about dying in respiratory distress. The desire to avoid breathlessness was poignantly clear.

1. "I've always said I'm not afraid of dying 'cause I know where I'm going. But when I get short of breath I get scared - I don't know why - I shouldn't. I think smothering to death is a hard way to go." (EL6831W)

2. "You're smothering when you're having one of them attacks... I'm constantly talking to myself about calming down, but when you're having one of those attacks it's hard to actually do it." (ESTM\#2570)

3. "We had like a snowstorm and I got stuck at the end of a 500 foot driveway, uphill, 8 inches of snow on the ground, and it's snowing and my husband was out of town. I had to make it up the driveway and you know halfway up I'm so out of breath I want to just sit down and die, and I'm thinking, 'this is just wrong, I shouldn't be out of breath already, you know, and you just have to take it one step at a time, take one step, stop and rest, take another step, stop and rest ... and I'm thinking, 'I hope I don't pass out, I'm the only one here, I won't be found for days.'" (KM9108W)

4. "I guess my greatest fear is dying. That would be a hard way to go. I mean, it's not like a bullet or getting hit by a car." (JM8520H)

\section{Desire for improved care}

The theme of desire for improved care was frequently expressed by patients (62\%) and focused on lack of self-management support and a general lack of understanding of their condition including how to care for themselves. Patients were confused, frustrated, and wanted to learn more about their illness. They had difficulty knowing how to get their informational and medical needs met.

1. "It's crazy, you're butt-deep in it and they don't tell you anything, they just say, 'you have COPD'. It's expected that you know what to do." (CMTM\#4649)

2. "Nobody's ever actually explained it to me." (LS5204F)

3. "I know there's a better exercise than what I do that will help me." (AW7500B)

4. "Just about anything that I can learn that will help." (BL7976R)

5. "Anything that I can learn ... anything that'll help me, I'll try it. Maybe ya'll know something I don't. I hope you do." (EL6831W)

\section{Discussion}

\section{Main findings}

These in-depth interviews of patients with COPD were conducted to learn about patients' concerns, fears, learning needs, barriers, facilitators, goals, and expectations concerning self-management of COPD and to guide delivery of cognitive-behavioural intervention as part of self-management support. In this context, three main themes with seven associated sub-themes were identified. Given that these themes occurred in response to questions focused on patients' needs and goals, they may be interpreted as reflecting the patients' desire and motivation to overcome losses and fears and to access better information and care.

Patients experienced the loss of their independence, hobbies, activities of daily living, and social connections and they wished to regain them. Moreover, fearful experiences associated with uncontrolled breathlessness were a major concern, and patients were highly motivated to avoid these. Further, gaining information and a desire to learn about new medications and new methods that might improve outcomes was a major interest of many of the patients we interviewed. Designing cognitive-behavioural interventions to address these areas of motivation may improve outcomes in selfmanagement of COPD.

\section{Strengths and limitations of this study}

Confidence in these findings needs to be assessed in the context of a number of factors that may affect the internal and external validity of qualitative research. ${ }^{14}$ However, for assessing patients' selfmanagement goals and concerns, the qualitative design allowed patients to express their perspectives fully without external bias. Moreover, use of standardised methods, multiple coders, and an iterative process for theme identification provides strong evidence for internal validity of the findings. While participants did not provide feedback on the findings, the three themes were confirmed by the interviewer, who also emphasised the patients' strong emotional reactions of fear about loss of independence, suggesting some interaction between the themes of loss and fear. In addition, the sample size and full spectrum of disease severity and co-morbidities suggest that the results are generalisable to patients in primary and specialty care. However, because of the potential for social and cultural differences that may affect patients' perceptions, ${ }^{15}$ the results should be generalised with caution to ethnic groups other than nonHispanic whites.

\section{Interpretation of findings in relation to previously published work}

While a number of qualitative and quantitative studies have been conducted to examine various aspects of patients' knowledge and perceptions about COPD, few have specifically examined patients' perspectives concerning barriers, facilitators, and personal goals for self-management in representative samples of patients. By focusing on patients' perceptions of their needs, we hoped to guide development of cognitive-behavioural interventions for selfmanagement support. The goal of self-management support is to 'change patients' behaviour by increasing the patients' self-efficacy and knowledge'. 7,16

Gaps in patients' knowledge and health literacy - that is, the ability to obtain, understand, and act on health care information ${ }^{17,18}$ - have been described in a number of qualitative studies ${ }^{19-25}$ and surveys. ${ }^{26-29}$ Moreover, while patients who complete pulmonary rehabilitation report improvements in disease knowledge, medication use, awareness of action plans for exacerbations, exercise, and diet, these changes in knowledge are not associated with improved outcomes. ${ }^{27}$ This lack of association between improved knowledge and health outcomes is a consequence of the fact that health-related behaviours are affected by a number of 
factors other than knowledge including emotional adjustment to illness, self-efficacy, motivation, self-management skills, social support, environmental obstacles, and ongoing support. ${ }^{16}$

The potential influence of these other factors on patient behaviours and health outcomes has been examined previously in qualitative studies ${ }^{20,30-37}$ and a smaller number of surveys. ${ }^{26,28,38}$ From these earlier studies, major factors that may affect living with COPD and self-care include lack of knowledge, inadequate communication with providers, loss of social support, multiple co-morbidities, medication issues, physical limitations, loss of control, loss of meaningful activities, fear of getting worse, daily uncertainty, helplessness, and emotional impact of illness. Questions about the external validity of these previous results arise because many of the earlier qualitative studies comprised selected patients (e.g. posthospitalisation, post-rehabilitation, end-stage disease, advertisements, research registries) and small sample sizes. However, the consistency of our results with these earlier findings strengthens their clinical relevance. Further, the fact that the interview used in this study focuses on needs, goals, and overcoming barriers indicates that the patients' concerns are more than simply concern - they are also motivational. These motivations may be accessed in cognitivebehavioural interventions to create important behavioural change.

Implications for future research, policy and practice Growing evidence suggests that self-management support is a necessary component of effective chronic illness care, ${ }^{16}$ which is recognised in a number of recent policy initiatives to facilitate the adoption of self-management support by health systems in the USA ${ }^{39}$ and worldwide. ${ }^{40}$ While the ultimate goal of self-management support is improved functional and health outcomes through patients' health-related behaviours (e.g. medical management adherence, smoking cessation, physical activity, diet), there remain a number of questions about specific content and how to deliver selfmanagement support in general, ${ }^{16}$ and for COPD in particular. ${ }^{7}$ The results of our study emphasise patients' goals and expectations that must be addressed when providing self-management support for general COPD self-care and related to enhancing physical activity. For clinicians, a consistent area of concern is the desire among patients for improved care, which is consistent with findings from previous investigations that quality of communication and duration of the relationship between physician and patient affects health literacy and self-efficacy of patients. ${ }^{41}$ Moreover, poor physician communication is a barrier to self-management, ${ }^{35}$ and communication style has a major influence on making commitment to specific behavioural change goals and plans. ${ }^{42}$ Further research is needed to determine the best cognitive-behavioural methods for encouraging COPD patients to convert their motivation to overcome losses and fears, and their need for information into the actual behaviour change that will help them manage their illness better.

\section{Conclusions}

While there have been a growing number of efficacious pharmacological and non-pharmacological interventions for patients with COPD,' their effectiveness will be limited without selfmanagement support to assist patients in adopting behaviours that contribute to improved health. Our results suggest that the content of self-management support for patients with COPD needs to focus on addressing patients' needs for improved health literacy, fears associated with uncertainty, disease progression, and suffering; and expectations about overcoming or replacing losses and desire for improved care. Attention to these themes may enhance patient selfefficacy and motivation to engage in more comprehensive selfmanagement.

\section{Handling editor Dianne Goeman}

Acknowledgements The authors thank Jennifer Peoples and Rennie Russo who enrolled patients and conducted interviews, and Jamile Ashmore for input during the conceptual stages of the project.

Conflicts of interest The authors declare that they have no conflicts of interest in relation to this article.

Contributorship KW oversaw the analysis and interpretation of patient interviews, drafted the manuscript, and coordinated revising the manuscript. AC, $J R M, S L$ and KL participated in data analysis and interpretation, and reviewing and revising the manuscript. SB, BJ, FS and KS assisted with data management, analysis, and reviewing and revising the manuscript. DC designed and implemented the original research, conceptualised the qualitative analysis, and participated in revising the manuscript.

Funding This study was funded by the National Institutes of Health National Heart, Lung, and Blood Institute R18 HL092955.

\section{References}

1. The Global Initiative for Chronic Obstructive Lung Disease (GOLD) 2011. Available from: http://www.goldcopd.org/ (accessed 16 Jan 2012).

2. Heffner JE, Mularski RA, Calverley PM. COPD performance measures: missing opportunities for improving care. Chest 2010;137(5):1181-9. http://dx.doi.org/10.1378/chest.09-2306

3. Frieden TR. A framework for public health action: the health impact pyramid. Am J Public Health 2010;100(4):590-5. http://dx.doi.org/10.2105/AJPH.2009.185652

4. Coleman K, Austin BT, Brach C, Wagner EH. Evidence on the chronic care model in the new millennium. Health Affairs 2009;28(175):76-85

http://dx.doi.org/10.1377/hlthaff.28.1.75

5. Institute of Medicine (IOM). Priority areas for national action: transforming health care quality. Washington, DC: National Academy Press, 2003. Available from: http://www.iom.edu/Reports/2003/Priority-Areas-for-National-Action-TransformingHealth-Care-Quality.aspx (accessed 16 Jan 2012).

6. Effing T, Monninkhof EM, van der Valk PD, et al. Self-management education for patients with chronic obstructive pulmonary disease. Cochrane Database Syst Rev 2007;17(4):CD002990. http://dx.doi.org/10.1002/14651858.CD002990.pub2

7. Effing TW, Bourbeau J, Vercoulen J, et al. Self-management programmes for COPD: moving forward. Chron Respir Dis 2012;9:27-35. http://dx.doi.org/10.1177/1479972311433574.

8. Coultas D. Randomized trial of physical activity self-management intervention for patients with COPD. Available from: http://clinicaltrials.gov/ct2/show/ NCT01108991?term=coultas\&rank=1 (accessed 5 Feb 2012).

9. Celli BR, Cote CG, Marin JM, et al. The body-mass index, airflow obstruction, dyspnea, and exercise capacity index in chronic obstructive pulmonary disease. $N$ Engl J Med 2004;350(10):1005-12. http://dx.doi.org/10.1056/NEJMoa021322

10. Schünemann HJ, Goldstein R, Mador MJ, et al. A randomised trial to evaluate the self-administered standardised chronic respiratory questionnaire. Eur Respir J 2005;25:31-40. http://dx.doi.org/10.1183/09031936.04.00029704

11. Friedman B, Heisel MJ, Delavan RL. Psychometric properties of the 15-item Geriatric Depression Scale in functionally impaired, cognitively intact, community dwelling elderly primary care patients. J Am Geriatr Soc 2005;53:1570-6. http://dx.doi.org/10.1111/j.1532-5415.2005.53461.x

12. Glaser B, Strauss A. The Discovery of Grounded Theory. Chicago: Aldine, 1967.

13. Pope C, Ziebland S, Mays N. Qualitative research in health care. BMJ 2000;320:1146. http://dx.doi.org/10.1136\%2Fbmj.320.7227.114

14. Tong A, Sainsbury P, Craig J. Consolidated criteria for reporting qualitative research (COREQ): a 32-item checklist for interviews and focus groups. Int J Qual Health Care 2007;19(6):349-57. http://dx.doi.org/10.1093/intqh/mzm042 
15. Sheridan N, Kenealy T, Salmon E, Rea H, Raphael D, Schmidt-Busby J. Helplessness, self blame and faith may impact on self management in COPD: a qualitative study. Prim Care Respir J 2011;20(3):307-14. http://dx.doi.org/10.4104/pcri.2011.00035

16. Agency for Healthcare Research and Quality (AHRQ). Patient self-management support programs: an evaluation. 2007. Available from: http://www.ahrq.gov/qual/ptmgmt/ptmgmt.pdf (accessed 13 Feb 2012).

17. Roberts NJ, Ghiassi R, Partridge MR. Health literacy in COPD. Int J COPD 2008;3(4):499-507

18. Institute of Medicine 2011. Health Literacy Implications for Health Care Reform: Workshop Summary. 2011. Available from: http://www.nap.edu/catalog.php?record_id=13056\#toc (accessed 5 Feb 2012).

19. Bayliss EA, Steiner JF, Fernald DH, Crane LA, Main DS. Descriptions of barriers to selfcare by persons with comorbid chronic diseases. Ann Fam Med 2003;1(1):15-21. http://dx.doi.org/10.1370/afm.4

20. Caress A, Luker K, Chalmers K. Promoting the health of people with chronic obstructive pulmonary disease: patients' and carers' views. J Clin Nurs 2010;19(34):564-73. http://dx.doi.org/10.1111/j.1365-2702.2009.02982.x

21. Gruffydd-Jones K, Langley-Johnson C, Dyer C, Badlan K, Ward S. What are the needs of patients following discharge from hospital after an acute exacerbation of chronic obstructive pulmonary disease (COPD)? Prim Care Respir J 2007;16(6):363-8. http://dx.doi.org/10.3132/pcri.2007.00075

22. Habraken JM, Pols J, Bindels PJE, Willems DL. The silence of patients with end-stage COPD: a qualitative study. $\mathrm{Br}$ J Gen Pract 2008;58:844-9. http://dx.doi.org/10.3399/bjgp08X376186

23. Nelson JE, Kinjo K, Meier DE, Ahmad K, Morrison RS. When critical illness becomes chronic: informational needs of patients and families. J Crit Care 2005;20(1):79-89. http://dx.doi.org/10.1016/j.jcrc.2004.11.003

24. Rodgers S, Dyas J, Molyneux AW, Ward MJ, Revill SM. Evaluation of the information needs of patients with chronic obstructive pulmonary disease following pulmonary rehabilitation: a focus group study. Chron Respir Dis 2007:4:195-203. http://dx.doi.org/10.1177/1479972307080698

25. Wilson JS, O'Neill B, Reilly J, MacMahon J, Bradley JM. Education in pulmonary rehabilitation: the patient's perspective. Arch Phys Med Rehabil 2007;88(12):17049. http://dx.doi.org/10.1016/j.apmr.2007.07.040

26. Barr RG, Celli BR, Martinez FJ, et al. Physician and patient perceptions in COPD: the COPD Resource Network Needs Assessment Survey. Am J Med 2005;118(12):1415. http://dx.doi.org/10.1016/.amjmed.2005.07.059

27. Cicutto LC, Brooks D. Self-care approaches to managing chronic obstructive pulmonary disease: a provincial survey. Respir Med 2006;100(9):1540-6. http://dx.doi.org/10.1016/j.rmed.2006.01.005

28. Gruffydd-Jones K. A national strategy for the management of chronic obstructive pulmonary disease (COPD) in England: aiming to improve the quality of care for patients. Prim Care Respir J 2008;17(Suppl 1):S1-S8. http://dx.doi.org/10.3132/pcrj.2008.00071

29. Hernandez $\mathrm{P}$, Balter M, Bourbeau J, Hodder R. Living with chronic obstructive pulmonary disease: a survey of patients' knowledge and attitudes. Respir Med 2009;103:1004-12. http://dx.doi.org/10.1016/..rmed.2009.01.018

30. Berger BE, Kapella MC, Larson, JL. The experience of stigma in chronic obstructive pulmonary disease. West J Nurs Res 2011;33(7):916-32. http://dx.doi.org/10.1177/0193945910384602

31. Boyles CM, Bailey PH, Mossey S. Chronic obstructive pulmonary disease as disability: dilemma stories. Qual Health Res 2011;21(2):187-98. http://dx.doi.org/10.1177/1049732310383865

32. Cicutto $L$, Brooks $D$, Henderson $K$. Self-care issues from the perspective of individuals with chronic obstructive pulmonary disease. Patient Educ Couns 2004;55(2):16876. http://dx.doi.org/10.1016\%2Fj.pec.2003.08.012

33. Curtis JR, Engelberg R, Young JP, et al. An approach to understanding the interaction of hope and desire for explicit prognostic information among individuals with severe chronic obstructive pulmonary disease or advanced cancer. I Palliat Med 2008;11(4):610-20. http://dx.doi.org/10.1089/jpm.2007.0209

34. Ek K, Ternestedt BM. Living with chronic obstructive pulmonary disease at the end of life: a phenomenological study. J Adv Nurs 2008;62(4):470-8. http://dx.doi.org/10.1111\%2Fj.1365-2648.2008.04611.x

35. Fraser DD, Kee CC, Minick P. Living with chronic obstructive pulmonary disease: insiders' perspectives. J Adv Nurs 2006;55(5):550-8. http://dx.doi.org/10.1111\%2Fi.1365-2648.2006.03946.x

36. Jerant $A F$, von Friederichs-Fitzwater MM, Moore $M$. Patients' perceived barriers to active self-management of chronic conditions. Patient Educ Couns 2005;57(3):3007. http://dx.doi.org/10.1016/.pec.2004.08.004

37. Lindqvist $G$, Hallberg LR. Feeling of guilt due to self-inflicted disease: a grounded theory of suffering from chronic obstructive pulmonary disease (COPD). J Health Psychol 2010;15(3):456-66. http://dx.doi.org/10.1177/1359105309353646

38. Omachi TA, Katz PP, Yelin EH, et al. The COPD Helplessness Index: a new tool to measure factors affecting patient self-management. Chest 2010;137:823-30. http://dx.doi.org/10.1378/chest.09-0764.

39. Patient Protection and Affordable Care Act 2010 http://www.healthcare.gov/law/resources/authorities/patient-protection.pdf (accessed 5 Feb 2012).

40. Nuño R, Coleman K, Bengoa R, Sauto R. Integrated care for chronic conditions: the contribution of the ICCC Framework. Health Policy 2011 Nov 7 [Epub ahead of print]. http://dx.doi.org/10.1016/j.healthpol.2011.10.0066

41. Slatore CG, Cecere LM, Reinke LF, et al. Patient-clinician communication: associations with important health outcomes among veterans with COPD. Chest 2010;138(3):628-34. http://dx.doi.org/10.1378/chest.09-2328

42. Miller WR, Rose GS. Toward a theory of motivational interviewing. Am Psychol 2009;64(6):527-37. http://dx.doi.org/10.1037/a0016830

Available online at http://www.thepcrj.org 